\title{
University students' perceptions and factors contributing to obesity and overweigh in Southern of Morocco
}

\author{
Mohamed Boukrim ${ }^{1}$, Majdouline Obtel ${ }^{1,2}$, Laila Lahlou ${ }^{3}$, Rachid Razine ${ }^{1,2}$
}

1. Laboratoire of Biostatistics, clinical Research and Epidemiology- Faculty of Medicine and Pharmacy. Mohamed V University, RABAT, Morocco.

2. Social Medicine Laboratory (Public Health, Hygiene and Preventive Medicine) - Faculty of Medicine and Pharmacy. Mohamed V University, RABAT, Morocco.

3. Faculty of Medicine and Pharmacy, Ibn Zohr University, AGADIR, Morocco.

\section{Author details:}

Rachid Razine : Tél: +212537770421/33 +212537772981/82, Fax: +212537773701; Majdouline Obtel: Tél: +212537770421/33 +212537772981/82, Fax: +212537773701; Laila Lahlou: Tel: +212528227170, Fax:+212528217171; Mohamed Boukrim: Tél: +212537770421/33 +212537772981/82, Fax: +212537773701

\begin{abstract}
:
Background: Weight load is a cosmopolitan health problem. In Morocco, women are the most affected by the phenomenon since obesity has risen from $26.8 \%$ to $29.0 \%$.

Objective: To determine the prevalence of weight load and associated factors among female students in higher education. Methods: Data were collected by a questionnaire. Anthropometric measurements were made using a scale and a wall-mounted scale. Data were analysed by the statistical software SPSS version 13.0. Quantitative variables were described in mean \pm standard deviation. Factors associated with obesity were determined by binary logistic regression.

Results: About two-thirds of the students had a normal weight, $21 \%$ were overweight and 3\% were obese. In addition, $58 \%$ of students were physically inactive and $77 \%$ ate cake and fast food. In addition, $63 \%$ of students were dissatisfied with their weight. A significant relationship is found between level of primary education, type of establishment, cake and fast food consumption and weight load.

Conclusion: The results revealed that $24 \%$ of participants were weight load and had behavioral risk factors such as a sedentary lifestyle and an unbalanced diet, which requires the promotion of a healthy lifestyle among these students as well as psychological support for those dissatisfied with their body image.
\end{abstract}

Keywords: Weight load, obesity, overweight, perception, female students, higher education, Morocco.

DOI: https://dx.doi.org/10.4314/ahs.v21i2.56

Cite as: Boukrim M, Obtel M, Lablou L, Razine R. University students' perceptions and factors contributing to obesity and overweigh in Southern of Morocco. Afri Health Sci. 2021;21(2). 942-950. bttps:/ / dx.doi.org/ 10.4314/ abs.v21i2.56

\section{Introduction}

Overweight and obesity are defined as an abnormal or excessive accumulation of body fat that can be detrimental to health ${ }^{1}$. They have consequences for physical, psychological and social well-being. The health repercussions of being overweight are well known. It is a

\section{Corresponding author: \\ Mohamed Boukrim, \\ Higher Institute of Nursing and Health Techniques. Laayoune. Morocco. \\ Tél: + 212666100681 / + 212661210458. \\ E-mail address: m.boukrim@um5s.net.ma / \\ boukrim1967@gmail.com}

risk factor for type 2 diabetes, cardiovascular disease, hypertension, osteoarthritis and certain forms of cancer $^{2}$. Since 1975, the number of obesity cases worldwide has almost tripled. In 2016,39\% of adults aged 18 years and older were overweight and $13 \%$ were obese. Most of the world's population lives in countries where overweight and obesity kill more people than underweight ${ }^{3}$. In general, obesity is more prevalent among women than men. Approximately $30-82 \%$ of women in the Arab world are overweight and obese compared to $25-70 \%$ of men $^{4}$.

Weight load is a cosmopolitan phenomenon. It affects all countries, developed as well as developing. Studies on obesity in Eastern Mediterranean countries, showed License (https://creativecommons.org/licenses/BY/4.0), which permits unrestricted use, distribution, and reproduction in any medium, provided the original work is properly cited. 
that women in Bahrain and Egypt were more likely to be overweight or obese followed by women in Jordan, Syria and $\mathrm{Oman}^{4}$. In the Middle East, adults were reported to have the second highest body mass index in the world after those in North America 5 .

In Morocco, this prevalence has evolved between 2011 and 2018 from $50.8 \%$ to $53 \%$ in the general population, while obesity has increased from $17.9 \%$ to $20 \%$. Women are the most affected by this phenomenon. In fact, there has been an increase in the weight load from $61.5 \%$ to $63.4 \%$. Obesity increased from $26.8 \%$ to $29 \%{ }^{6,7}$.

Several factors were blamed for the scourge, such as lack of exercise, disturbed sleep, stress, ethnicity, gender, parental education, and family income ${ }^{8}$. Not to mention the influence of the media, family and peers on body satisfaction, with an overall predominance of the effects of media images on body image perception ${ }^{9}$ often leading to the adoption of aspects of westernization $^{10}$. Indeed, recent studies in the Eastern Mediterranean region have revealed westernized visions of ideal body image where the slimmer body image is considered to be better ${ }^{11}$.

Most studies in Morocco have focused on women and children in school, and there has been a lack of studies of the phenomenon among young adults in higher education institutions. The objective of our study was to study the prevalence of weight load and associated factors among young female students in public higher education institutions.

\section{Methods}

This is a cross-sectional observational study conducted in two public institutions of higher education located in the Province of Agadir, capital of the Souss region in Morocco.

These institutions welcome in addition to the students of this region, those of the 3 southern regions. They are the Higher Institute of Nursing and Health Techniques (HINHT) and the National School of Commerce and Management (NSCM). The data collection took place from April to May 2018.

The students were recruited from two institutions that were selected on the basis of the following criteria: accessibility to our field team, presence of a sufficient number of students from neighboring regions and whose officials agreed to the conduct of the study.
The study concerns 200 non-pregnant Moroccan female students over the age of 18 . The students had to meet the inclusion criteria and give their consent to participate in the survey. To calculate the sample size, we used the formula:

$\mathrm{n}=\mathrm{t}^{2} \times \mathrm{p} \times(1-\mathrm{p}) / \mathrm{m}^{2}$

Where $\mathrm{t}$ is the $95 \%$ confidence level, $\mathrm{p}$ is the estimated prevalence of the obese population, and $\mathrm{m}$ is the margin of error (set at 5\%).

The prevalence of obesity is estimated at $15 \%$ in the same institution ${ }^{12}$. Thus, 195 subjects were considered necessary for inclusion to obtain statistically significant results. The total number of student was 200 .

Data Collection was done through a self-administered questionnaire on sociodemographic data (age, level of education of parents, marital status, parents' monthly income), sedentary lifestyle, diet and body image perception. The study was conducted with the free and informed consent of the participants and with respect for the anonymity and the confidentiality of the information.

The anthropometric parameters (weight and height) of the students were measured using the mechanical personal scale marketed name SECA, calibrated in kilograms and a wall scale graduated in centimeters. The measurement of weight (in $\mathrm{kg}$ ) was carried out on participants with no shoes and in light clothing. Height (in meters) was measured in subjects with their feet flat on the floor, their backs, buttocks and heels pressed against the vertical board of the scale and their heads placed in a horizontal position so that the line of vision was perpendicular to the body.

The body mass index (BMI) was calculated by the following formula: BMI $\left(\mathrm{kg} / \mathrm{m}^{2}\right)$ = weight (in $\left.\mathrm{kg}\right) /$ height2 (in $\mathrm{m}^{2}$ ). BMI is recognized as international criteria for assessing corpulence. According to the thresholds adopted by the World Health Organization: underweight is defined as a BMI equal to or greater than $18.5 \mathrm{~kg} / \mathrm{m}^{2}$, overweight is defined as a BMI equal to or greater than $25 \mathrm{~kg} / \mathrm{m}^{2}$ and obesity as a BMI equal to or greater than $30 \mathrm{~kg} / \mathrm{m}^{2}$.

The students' perception of body image was measured by the Silhouette Rating Scale13 or Stunkard Figurines, consisting of a series of nine figures (or silhouettes) representing, from the front, the female body from the leanest to the largest. Each student is invited to indicate which one corresponds best to her (perceived body) 
and which one corresponds to what she would like to be (ideal body).

Data were analysed using the statistical data processing software SPSS version 13.0. Qualitative variables were described in numbers and percentages and then compared by chi-square and Fisher exact tests considering the conditions of application of each one. Quantitative variables were described in mean \pm standard deviation. The prevalence of obesity/overweight was calculated by relating the number of overweight and obese students to the total number of students.

Factors associated with obesity/overweight were determined by binary logistic regression to calculate the odds ratios (OR) and a 95\% confidence interval (CI).
In all the analyses, $\mathrm{P} \leq 0.05$ was considered statistically significant.

\section{Results}

The socioeconomic characteristics and the anthropometric parameters of participants are presented in Table 1 . The distribution by ethnicity shows that $48.5 \%$ and 44\% were of Amazigh and Arab ethnicity respectively. More than $52.5 \%$ of the parents had a monthly income of at least 7500 Moroccan Dirham (MAD).

The mean age was $19.64 \pm 1.22$ years, with a mean weight of $58.01 \pm 8.86 \mathrm{Kg} \mathrm{kg}$ and an average height of $1.618 \mathrm{~m} \pm 5.961 \mathrm{~cm}$. For body mass index (BMI) average was $22.20 \pm 3.525 \mathrm{~kg} / \mathrm{m}^{2}$.

Table 1: Distribution of female students according to socio-demographic characteristics and body mass index $(\mathrm{n}=200)$.

\begin{tabular}{|c|c|c|c|}
\hline Variables & $\begin{array}{c}\text { Mean age } \pm \\
\text { standard deviation }\end{array}$ & $\mathbf{N}$ & $\%$ \\
\hline Age & $19,65 \pm 1.22$ & - & - \\
\hline BMI & $22.20 \pm 3.525 \mathrm{Kg} / \mathrm{m}^{2}$ & - & - \\
\hline Poids & $58.01 \pm 8.86 \mathrm{Kg}$ & - & - \\
\hline Taille & $1.62 \mathrm{~m} \pm 5.961 \mathrm{~cm}$ & - & - \\
\hline Level of study & $1.02 \mathrm{mI}-5.701 \mathrm{~cm}$ & & \\
\hline 1st year & & 86 & 43,00 \\
\hline 2nd year & & 59 & 29,50 \\
\hline 3rd year & & 55 & 27,50 \\
\hline \multicolumn{4}{|l|}{ Ethnicity } \\
\hline Amazigh & & 97 & 48,50 \\
\hline Arab & & 88 & 44,00 \\
\hline Saharian & & 15 & 7,50 \\
\hline \multicolumn{4}{|l|}{ Marital status } \\
\hline Single & & 197 & 98,50 \\
\hline Married & & 02 & 1,00 \\
\hline Divorced & & 01 & 0,50 \\
\hline \multicolumn{4}{|l|}{ Education level of parents } \\
\hline Illiterate & & 34 & 17,00 \\
\hline Primary & & 41 & 20,50 \\
\hline Secondary & & 35 & 17,50 \\
\hline Academic & & 90 & 45,00 \\
\hline \multicolumn{4}{|l|}{ Parents' monthly } \\
\hline income (Moroccan Dirham) & & 17 & 8,50 \\
\hline Less than 2500 & & 54 & 27,00 \\
\hline $2500-5000$ & & 34 & 17,00 \\
\hline $5000-7500$ & & 42 & 21,00 \\
\hline $7500-10000$ & & 53 & 26,50 \\
\hline More than 10000 & & & \\
\hline \multicolumn{2}{|l|}{ Body mass index (BMI) in $\mathrm{Kg} / \mathrm{m} 2$} & 32 & 16.00 \\
\hline Less than 18.5 & & 120 & 60,00 \\
\hline$[18.5-25[$ & & 42 & 21,00 \\
\hline$[25-30[$ & & 06 & 3,00 \\
\hline$[30-35[$ & & & \\
\hline
\end{tabular}


The prevalence of obesity and overweight in our study was $21 \%$ and $3 \%$ respectively.

Table 2 shows the anthropometric parameters of fe- male student by age strata. The results indicate that the mean of body mass index increased with age up to 22 years.

Table 2: Anthropometric parameters of participants by age strata.

\begin{tabular}{lcccc}
\hline & Less than 18 years & $18-19$ & $20-22$ & More than 22 years \\
BMI $(\mathrm{kg} / \mathrm{m} 2)$ & $22,11 \pm 3.44$ & $22,17 \pm 3.84$ & $22,37 \pm 2,77$ & $21,89 \pm 4,25$ \\
Weight $(\mathrm{kg})$ & $58,70 \pm 8.49$ & $57,64 \pm 9.29$ & $58,43 \pm 8,10$ & $55,33 \pm 12,50$ \\
Height $(\mathrm{m})$ & $1,63 \pm 0,05.59 \mathrm{~cm}$ & $1,61 \pm 6.012 \mathrm{~cm}$ & $1,616 \pm 6.23 \mathrm{~cm}$ & $1,59 \pm, 02.89 \mathrm{~cm}$ \\
\hline
\end{tabular}

\section{Perception and satisfaction with weight}

Almost two-thirds $(126,63 \%)$ of the students were dissatisfied with their body weight and $65.5 \%$ didn't want to gain weight. The reasons given for this refusal were reading magazines and the media, family and friends with proportions of $24 \%, 23 \%$ and $20 \%$ respectively. As for perceptions of obesity and overweight, more than three-quarters considered obesity as a disease and the rest as normal or a sign of beauty.

\section{Physical activity and sedentary lifestyle}

The study revealed that more than half of the female students $(58 \%)$ were not physically active. Of those students who were active, only $34 \%$ were active daily or often. As for the time spent in front of a television screen, $47 \%$ of the population studied spent more than 2 hours a day in front of it. Concerning eating cake and fast food, $29.5 \%$ of the students said they did it daily (table 3).

Table 3: Weight load by student's perceptions and behaviors $(n=200)$.

\begin{tabular}{|c|c|c|c|}
\hline \multirow{2}{*}{ Variables } & \multicolumn{3}{|r|}{$\%$} \\
\hline & $\mathbf{N}$ & $\%$ & $\mathrm{BMI}>25 \mathrm{Kg} / \mathrm{m}^{2}$ \\
\hline \multicolumn{4}{|l|}{ Satisfaction with your weight* } \\
\hline No & 125 & 62.50 & 32 \\
\hline Yes & 75 & 37.50 & 09.30 \\
\hline \multicolumn{4}{|l|}{ Desire for gaining weight } \\
\hline No & 131 & 65.5 & 34.40 \\
\hline Yes & 69 & 33.50 & 2.90 \\
\hline \multicolumn{4}{|l|}{ Practice of physical activity } \\
\hline No & 115 & 57.50 & 26.1 \\
\hline Yes & 85 & 42.50 & 20 \\
\hline \multicolumn{4}{|l|}{ Frequency of physical activity } \\
\hline Daily & 14 & 7 & 0 \\
\hline Often & 54 & 27 & 24.1 \\
\hline Rarely/never & 132 & 66 & 25 \\
\hline \multicolumn{4}{|c|}{ Perception of obesity and overweight } \\
\hline Normal & 42 & 21 & 14.3 \\
\hline Disease & 158 & 79 & 25.9 \\
\hline \multicolumn{4}{|l|}{ TV watching frequency } \\
\hline Less than 2 hours a day & 107 & 53.5 & 20.6 \\
\hline 2:00 a.m.-4:00 a day. & 62 & 31 & 24.2 \\
\hline More than 4 hours a day & 31 & 15.5 & 32.3 \\
\hline \multicolumn{4}{|c|}{ Frequency of consumption of sugar/fast-food } \\
\hline Always & 59 & 29.5 & 37.3 \\
\hline Often & 95 & 47.5 & 17.9 \\
\hline Rarely & 46 & 23 & 17.4 \\
\hline
\end{tabular}

For the perception of body image, three quarters $(75.5 \%)$ of the students had chosen the image that really represented them. In fact, $74.16 \%$ of students with normal BMIs chose figures 3 and 4, which represented normal body images and almost all $91.50 \%$ of overweight or obese students considered figures 5 to 9 to be their current body images.
As for the perception of the ideal body, $91 \%$ of normal-weight and $81 \%$ of overweight students chose Figures 3 and 4 as the ideal body image. However, $40 \%$ and $20 \%$ of the obese students selected images 5 and 6 corresponding to overweight and obesity respectively (Figure 1 and Table 4). 


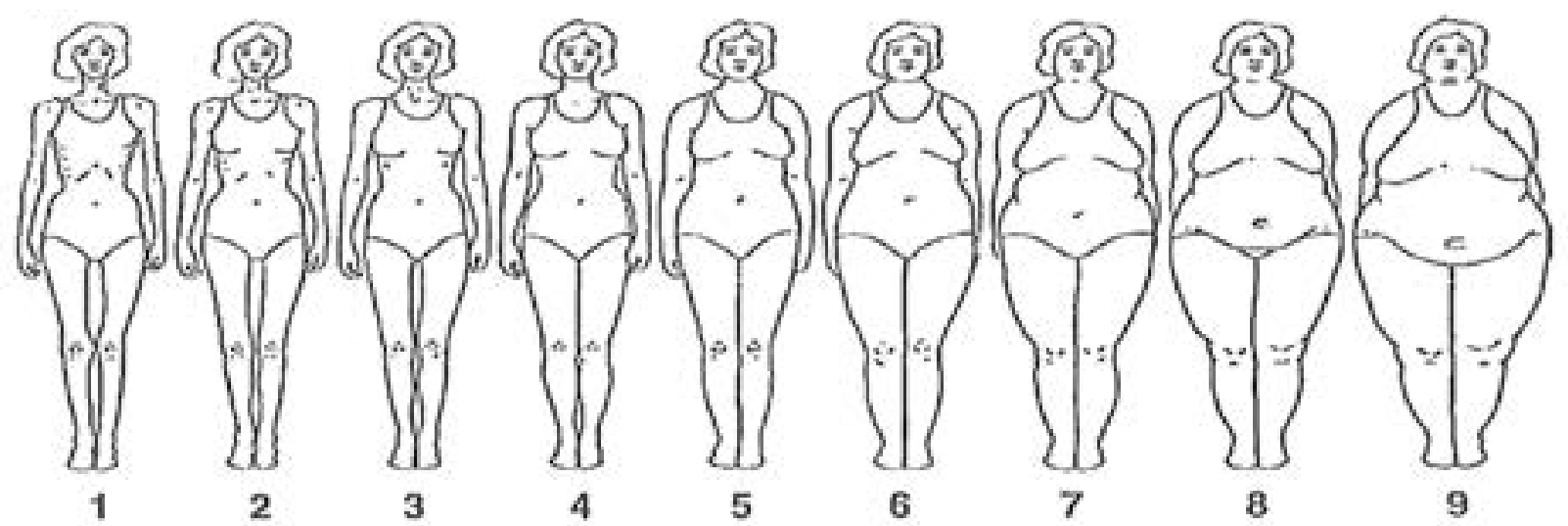

Figure 1: Stunkard Figurines representing the female body from the leanest to the largest

Table 4: Proportion of students as a function of selected figures

\begin{tabular}{|c|c|c|c|c|c|c|c|c|c|c|c|}
\hline \multirow{2}{*}{$\begin{array}{l}\text { Weight } \\
\text { load }\end{array}$} & \multirow{2}{*}{ Number } & \multirow{2}{*}{ Silhouette } & \multicolumn{9}{|c|}{ Figure Number } \\
\hline & & & 1 & 2 & 3 & 4 & 5 & 6 & 7 & 8 & 9 \\
\hline \multirow{2}{*}{$\begin{array}{l}\text { Normal } \\
\text { weight }\end{array}$} & \multirow{2}{*}{120} & $\begin{array}{l}\text { Current } \\
\text { silhouette }\end{array}$ & 3.33 & 7.5 & 35.83 & 38.33 & 13.33 & 0.83 & 0.83 & 0.0 & 0.0 \\
\hline & & $\begin{array}{l}\text { Ideal } \\
\text { Silhouette }\end{array}$ & 0.83 & 3.33 & 34.16 & 56.66 & 5.0 & 0.0 & 0.0 & 0.0 & 0.0 \\
\hline \multirow{2}{*}{ Overweight } & \multirow{2}{*}{42} & $\begin{array}{l}\text { Current } \\
\text { silhouette }\end{array}$ & 0.0 & 2.4 & 2.4 & 4.76 & 42.85 & 26.19 & 14.28 & 0.14 & 0.0 \\
\hline & & $\begin{array}{l}\text { Ideal } \\
\text { Silhouette }\end{array}$ & 0.0 & 2.38 & 16.66 & 64.28 & 16.66 & 0.0 & 0.0 & 0.0 & 0.0 \\
\hline \multirow{2}{*}{ Obesity } & \multirow{2}{*}{5} & $\begin{array}{l}\text { Current } \\
\text { silhouette }\end{array}$ & 0.0 & 0.0 & 0.0 & 0.0 & 20.0 & 20.0 & 0.0 & 40.0 & 20.0 \\
\hline & & $\begin{array}{l}\text { Ideal } \\
\text { Silhouette }\end{array}$ & 0.0 & 0.0 & 0.0 & 40.0 & 40.0 & 20.0 & 0.0 & 0.0 & 0.0 \\
\hline
\end{tabular}

$\mathrm{BMI}=$ body mass index

The univariate logistic analysis revealed that the sugar intake, parental primary education and study institution were significantly associated with weight load (Table 5). 
Table 5: Factors associated with the weight load among female students in higher education in southern Morocco in univariate analysis $(n=200)$.

\begin{tabular}{|c|c|c|c|c|}
\hline Variables & OR & IC à $95 \%$ & $\mathbf{p}$ & $\begin{array}{c}\% \\
\text { BMI }>25 \mathrm{Kg} / \mathrm{m}^{2}\end{array}$ \\
\hline Age & 0.97 & {$[0.71-1.21]$} & 0.58 & \\
\hline \multicolumn{5}{|l|}{ Education level } \\
\hline 1st year & 1 & & & 19.8 \\
\hline 2nd year & 1.26 & {$[0.57-2.81]$} & 0.57 & 23.7 \\
\hline 3 rd year & 1.66 & {$[0.76-3.66]$} & 0.20 & 29.1 \\
\hline \multicolumn{5}{|l|}{ Ethnicity: } \\
\hline Amazigh & 1 & & & 20.6 \\
\hline Arab and Sahrian & 1.37 & {$[0.71-2.64]$} & 0.35 & 26.20 \\
\hline \multicolumn{5}{|l|}{ Study institution } \\
\hline NSCG & 1 & & & 17.0 \\
\hline HINHT & 2.09 & {$[1.07-4.11]$} & 0.032 & 30.0 \\
\hline \multicolumn{5}{|l|}{ Education level of parents: } \\
\hline Illiterate & 1.04 & {$[0.39-2.76]$} & 0.94 & 20.6 \\
\hline Primary & 2.31 & {$[1.02-5.23]$} & 0.04 & 36.6 \\
\hline Secondary & 1.00 & {$[0.38-2.65]$} & 1.00 & 20.0 \\
\hline University & 1 & & & 20.0 \\
\hline \multicolumn{5}{|c|}{ Parental income (Moroccan Dirham) } \\
\hline Less than 5000 & 1.27 & {$[0.61-2.64]$} & 0.51 & 25.4 \\
\hline 5000 to 7500[ & 1.35 & {$[0.54-3.35]$} & 0.52 & 26.5 \\
\hline Higher than 7500 & 1 & & & 21.1 \\
\hline \multicolumn{5}{|l|}{ TV watching duration } \\
\hline Less than $2 \mathrm{~h}$ & 1 & & & 20.6 \\
\hline $2 \mathrm{~h}$ to $4 \mathrm{~h}$ & 0.54 & {$[0.22-1.32]$} & 0.40 & 24.2 \\
\hline Higher than $4 \mathrm{~h}$ & 0.67 & {$[0.26-1.73]$} & 0.41 & 32.3 \\
\hline \multicolumn{5}{|l|}{ Physical exercises } \\
\hline No & 0.71 & {$[0.36-1.39]$} & 0.32 & 26.1 \\
\hline Yes & 1 & & & $\begin{array}{l}20.1 \\
20.0\end{array}$ \\
\hline \multicolumn{5}{|l|}{ Sugar and fast food using } \\
\hline Always & 2.82 & {$[1.12-7.14]$} & 0.03 & 37.3 \\
\hline Often & 1.03 & {$[0.41-2.61]$} & 0.94 & 17.9 \\
\hline Rarely & 1 & & & 17.4 \\
\hline
\end{tabular}

BMI $=$ body mass index IC: Confidence interval OR: Odds Ratio

HINHT: Higher Institute of Nursing and Health Techniques

NSCM : National School of Commerce and Management.

\section{Discussion}

This survey investigated the prevalence of overweight and obesity and associated factors among female students at two institutions of higher education. In this study, almost a quarter of the female students were overweight. In Marrakech $15.7 \%$ of female medical students were overweight and $1.3 \%$ obese $^{12}$. In other study conducted in the School of Medicine and Health Science of the University of Development Studies in Ghana, obesity was $4.5 \%$ among female students ${ }^{14}$. At the Universities of Douala and Nangui Abrogoua in Côte d'Ivoire similar results for overweight $(26.44 \%)$ were found and for obesity the prevalence was $23 \% 0^{15,16}$. At the University of Assuit in Egypt, a study revealed that the prevalence of overweight is $24.6 \%{ }^{11}$ while it is $33.6 \%$ among adolescent girls in Dubai in the United Arab Emirates, $20.5 \%$ of whom were obese ${ }^{10}$. The observed differences could be explained by the size of the samples studied, the context of the study, the eating habits and the change in perceptions of overweight and obesity.

Despite the low prevalence of obesity recorded and the low number of female students of Saharawi ethnicity, data analysis also showed that among female students of Saharawi ethnicity, the prevalence of obesity $(6.66 \%)$ was three times higher than among students of other ethnicities (2.27\% among Arabs and 2.06\% among Amazigh). These results confirmed those of the study conducted among Sahrawi women in Laayoune ${ }^{17}$. However, there was no significant difference between BMI (obesity and overweight) and ethnic origin.

Univariate logistic regression analysis showed a significant relationship between parents' primary education level and weight load (OR=2.31 IC95\% $=[1.02-5.23])$. Parental income is not associated with the occurrence of obesity/overweight among female students. These results contradict those of other studies ${ }^{16,18}$. This may 
be explained by the nature of the population studied -by these studies- which is composed of adult, non-student women with varying levels of education.

Several other factors conditioned the development of obesity and overweight. Among the students who practiced physical exercise, $58.8 \%$ were of normal weight, unlike the students who did not (58\%), who were $26 \%$ overweight. Similar results among medical students revealed that among students who practiced sports, $88.8 \%$ were of normal weight and $22.8 \%$ of the others were overweight and obese ${ }^{12}$. However, no association was found between sport practice and obesity/overweight. Studies have shown that eating high-calorie, low-nutrient foods promote overweight and obesity ${ }^{8}$. As a result, the trend towards fast food consumption, especially among young people, may increase energy intake and thus increase the risk of being overweight ${ }^{19}$. Indeed, the results of the study showed that the frequency of cake and fast food consumption had a significant relationship with overweight and obesity. So, among overweight and obese students, $77 \%$ always or often consumed them. Other studies have shown that $76.4 \%$ of overweight and obese students consumed sweetened products and $33.3 \%$ consumed fat ${ }^{12}$.

The media (magazines, television and social networks) are important in changing the perception of the ideal body image. The study indicated that exposure to these media was positively related to the desire to lose weight. Our results are comparable to those of other studies in Western and Arab countries. Exposure to magazines ${ }^{20}$ and television ${ }^{21}$ was strongly associated with the desire to lose weight and therefore with dissatisfaction with body image among women. It was also reported that the more Arab women are exposed to Western models, the thinner they wanted to be. Similarly, authors ${ }^{22}$ have reported that Western advertising and media have induced Jordanian women to want to be thinner. In Egypt, exposure to fashion magazines and television was found to be significantly associated with women's body dissatisfaction and desire to be slimmer ${ }^{23}$. In general, students who frequently read women's magazines are two to six times more at risk of weight loss than those who rarely read those ${ }^{24}$. As for television, the risk of dieting for weight loss is higher among women and university students who are frequently exposed to fashion television channels ${ }^{24}$.

In terms of weight estimation, most participants were objective and our results were comparable to those reported in other studies ${ }^{21,25}$. However, there are others that have shown different results and that students tend to over- or underestimate their body weight ${ }^{10,26,27}$. As in other studies ${ }^{28}$, almost $2 / 3$ of the students were dissatisfied with their body weight although the majority of them had a normal BMI. This proportion is twice that published by other studies ${ }^{29}$. This could be explained by the westernization of societal behaviors and the change in perception by preferring thinness to overweight and obesity. This dissatisfaction made them want to adopt attitudes in favor of weight $\operatorname{loss}^{25,30}$. This choice was guided by factors such as friends, family, magazines and mass media ${ }^{10,31,32}$.

Our study also revealed that weight perception is not related to ethnicity. Nevertheless, more than half of the Saharian students $(n=15)$ considered overweight/ obesity to be normal, while more than three-quarters of the students from other ethnic groups considered it to be a disease. This difference could be explained by the cultural diversity between Moroccan ethnic groups and the effect of economic and socio-cultural modernization. Indeed, in the Arab culture, the thin woman was considered socially undesirable, while roundness is seen as a symbol of fertility and femininity ${ }^{33}$. However, this perception of Arab culture has changed, as thinner women are considered more attractive ${ }^{34}$. In African culture, even when black women perceive themselves to be overweight; they still see themselves as physically attractive ${ }^{35}$.

In southern Morocco, a fat woman is not only a sign of beauty but also of richness, while women's thinness is a sign of poverty ${ }^{36}$. However, others studies ${ }^{23}$ have found that $81 \%$ of female university students in Kuwait thought that men preferred thin women.

\section{Study limitations}

For administrative reasons and the collaboration of the responsible persons, only two institutes of higher education were selected.

The results obtained were based on the students' statements, given the difficulty of carrying out a prospective study to assess the diet and physical activity of female students. To reduce this limitation, before administering the questionnaire, participants were sensitized to the importance of their statements to the study.

\section{Study forces}

Anthropometric measurements were made directly on the students,

Choice of institutes with limited access and welcoming students from the 3 southern regions.

One of the few studies conducted among female students in higher education. 


\section{Conclusion}

The results of the study revealed that a quarter of the participants were overweight and had behavioral risk factors such as a sedentary lifestyle and an unhealthy diet, which requires the promotion of a healthy lifestyle among our young students as well as psychological support for those dissatisfied with their body image. As well, it is advisable to conduct further studies to evaluate the lifestyle of these students, especially the dietary aspect and physical activity.

\section{Ethics and consent to participate}

The information was obtained with the voluntary and informed consent of the participants. Similarly, the data collection instrument used (questionnaire) has the advantage of being impersonal since the information obtained cannot be linked to the participants and the subjects therefore feel more secure in terms of anonymity, confidentiality of information and respect for their privacy.

\section{Acknowledgements}

The authors would like to thank the study participants and the staff and management of the study site institutions for their support during data collection.

\section{Conflicts of interest}

The authors declare that they have no conflicts of interest.

\section{References}

1. World Health Organization, Obésité: prévention et prise en charge de l'épidémie mondiale: rapport d'une consultation de l'OMS. 2003, Genève: Organisation mondiale de la Santé.

2. Basdevant, A., Médecine de l'obésité. 2010, Elsevier Masson.

3. Organisation mondiale de la santé. Obésité et surpoids: principaux repères. 2016 [cited consulté le 15/12/2019; Available from: https://www.who.int/fr/ news-room/fact-sheets/detail/obesity-and-overweight. 4. Musaiger AO, Overweight and obesity in eastern mediterranean region: prevalence and possible causes. Journal of Obesity, 2011. 2011.

5. Yusuf S, et al., Obesity and the risk of myocardial infarction in 27000 participants from 52 countries: a case-control study. 2005. 366(9497): p. 1640-1649.

6. Minstère de la santé, Maroc, Enquête nationale sur les Facteurs de Risque communs des Maladies Non Transmissibles. 2017-2018.
7. Ministère de la prévision économique et du plan. Maroc, Enquête nationale sur les niveaux de vie des ménages 1998_99, in ENCDM-2011. 1998-1999. p. 34. 8. Dessureault J, Les Déterminants DE L'obésité et DU Surpoids Chez Les Jeunes Au Canada. 2010.

9. Grogan SJJ.o.h.p., Body image and health: Contemporary perspectives. Journal of Health Psychology, 2006. 11(4): p. 523-530.

10. Musaiger A, AB Zaal, R D'souza, Body weight perception among adolescents in Dubai, United Arab Emirates. Nutricion Hospitalaria, 2012. 27(6): p. 19661972.

11. EL Ansari W Dibba, Emily Labeeb, Shokria, et al. Body image concern and its correlates among male and female undergraduate students at Assuit University in Egypt. Global Journal of Health Science, 2014. 6(5): p. 105. 12. Karroumi MS. Paramètres anthropométriques et habitudes alimentaires chez les étudiants de médecine. Thèse de doctorat. 1988, Universite Cadi Ayyad.

13. Stunkard AT Sørensen, Schulsinger. Use of the Danish Adoption Register for the study of obesity and thinness. Res. Publ. Assoc. Res. Nerv. Ment. Dis, 1983. 60: p. 115.

14. Mogre VR Nyaba, S Aleyira. Lifestyle risk factors of general and abdominal obesity in students of the school of medicine and health science of the University of Development Studies, Tamale, Ghana. ISRN Obesity, 2014. 2014

15. Kouakou AYF, A Kamagate, AP Yapo. Prévalence De l'Obésité En Milieu Jeune En Côte d'Ivoire. Eur Sci J, 2017. 13: p. 241-248.

16. El Rhazi K et al. Prevalence of obesity and associated sociodemographic and lifestyle factors in Morocco. Public Health Nutrition, 2011. 14(1): p. 160-167.

17. Rahim S, A Baali. Etude de l'obésité et quelques facteurs associés chez un groupe de femmes marocaines résidentes de la ville de Smara (sud du Maroc). Antropo, 24 (1), 2011. 24(1): p. 43-53.

18. El Hsaïni $\mathrm{H}$ et al. Coexistence de surpoids/obésité et d'anémie chez les femmes de Rabat-Salé. Age (années), 2013. 36(4): p. 0-4.

19. Niemeier HMet al. Fast food consumption and breakfast skipping: predictors of weight gain from adolescence to adulthood in a nationally representative sample. Journal of adolescent Health, 2006. 39(6): p. 842849.

20. Hawkins $\mathrm{N}$ et al. The impact of exposure to the thin-ideal media image on women. Eating disorders, 2004. 12(1): p. 35-50.

21. Tiggemann M. Television and adolescent body im- 
age: The role of program content and viewing motivation. Journal of Social and Clinical Psychology, 2005. 24(3): p. 361-381.

22. Madanat H, SR Hawks, HN Angeles. Obesity and body size preferences of Jordanian women. Health Education \& Behavior, 2011. 38(1): p. 91-98.

23. Ragab S. Media Messages and Women'Body Perception in Egypt 2007. URL: http://digitalarchive. gsu. edu/communication-theses/30 consulté le 20/12/2019, 2012.

24. Musaiger AO, M Al-Mannai. Association between exposure to media and body weight concern among female university students in five Arab countries: a preliminary cross-cultural study. Journal of Biosocial Science, 2014. 46(2): p. 240-247.

25. Pica L et al. L'Enquête québécoise sur la santé des jeunes du secondaire 2010-2011 [The 2010-2011 health survey of high school students]. Lanaudière et ses territoires de RLS. L'activité Physique de Loisir et de Transport, 2012.

26. Lachaud $\mathrm{M}$ et al. Pratiques alimentaires et préoccupations corporelles chez les jeunes femmes. Journal de thérapie comportementale et cognitive, 2004. 14(3): p. 131-134.

27. Dansereau-Trahan É. Valeurs sous-jacentes aux programmes de santé publique visant la prévention de l'obésité: analyse de programmes. 2007.

28. Musaiger A. Body weight concern among female university students in five Arab countries-a preliminary cross-cultural study. Annals of Agricultural and Environmental Medicine, 2015. 22(2).

29. Masson E. Le mincir, le grossir, le rester mince: rapport au corps et au poids et pratiques de restrictions alimentaires. Corps de femmes sous influence.

30. Ata RN, AB Ludden, MM Lally. The effects of gender and family, friend, and media influences on eating behaviors and body image during adolescence. Journal of Youth and Adolescence, 2007. 36(8): p. 1024-1037.

31. Dany L, M Morin. Image corporelle et estime de soi: étude auprès de lycéens français. Bulletin de Psychologie, 2010(5): p. 321-334.

32. Nasser M. Culture and weight consciousness. Journal of Psychosomatic Research, 1988. 32(6): p. 573-577.

33. Eapen VAA Mabrouk, S Bin-Othman. Disordered eating attitudes and symptomatology among adolescent girls in the United Arab Emirates. Eating Behaviors, 2006. 7(1): p. 53-60.

34. Rasheed. Perception of body weight and self-reported eating and exercise behaviour among obese and non-obese women in Saudi Arabia. Public Health Nutrition, 1998. 112(6): p. 409-414.

35. Kumanyika S, JF Wilson, MJJo.t. ADA. Guilford-Davenport, Weight-related attitudes and behaviors of black women. 1993. 93(4): p. 416-422.

36. Rguibi M. L'obésité chez la femme marocaine Sahraouie: Prévalence, étiologies et facteurs de risque cardiovasculaires associés. 2005. 